\title{
УДК 159.9378.3
}

DOI https://doi.org/10.32840/2663-6026.2019.6-2.29

\author{
М. А. Волошенко \\ кандидат педагогических наук, \\ доцент кафедры психологии и социальной работы \\ Одесский национальный политехнический университет
}

А. В. Азаркина

старший преподаватель кафедры психологии и социальной работы Одесский национальный политехнический университет

\section{ИНДИВИДУАЛЬНО-ПСИХОЛОГИЧЕСКИЕ ОСОБЕННОСТИ ПЛАВСОСТАВА В УСЛОВИЯХ СТРЕСС-ФАКТОРА ПРОФЕССИОНАЛЬНОЙ ДЕЯТЕЛЬНОСТИ}

В статье проанализированы индивидуально-типологические особенности у членов плавсостава, формирующиеся под влиянием экстремальных фракторов работы в море, и проведена их типизация с учетом психофизиологических параметров.

Определено, что вопросы сохранения как психического, так и фризического здоровья моряка, его профилактика в межрейсовый период, улучшение условий профрессиональной деятельности, режима труда и отдыха являются наиболее актуальной психолого-социальной проблемой и требуют своего изучения.

Показано, что психофизическая реакция моряков на стресс имеет биполярную выраженность, которая представлена двумя типами: лабильным и ригидным. Степень напряжения регуляторных систем при равных условиях трудовой деятельности на судне в силу конституционально-генетической детерминации психофизиологических показателей индивида проявляется по-разному, что обусловливает возможность типизации плавсостава по выраженности специфических адаптивных реакций.

Анализ показателей ситуативного реагирования показал, что уровень тревожности обусловлен ситуацией профрессиональной деятельности.

Показано, что больщинство судовых специалистов имеют необходимые базовые свойства, лежащие в основе профрессионально важных качеств, связанных с работой в море.

Основой диффреренциации в ходе проведения исследования послужило состояние нейродинамических процессов обследуемых, отражающее проявление основных свойств нервной системы, подвижности и уравновешенности нервных процессов.

Проведено исследование индивидуально-типологических особенностей у плавсостава, формирующихся под влиянием экстремальных фракторов работы в море, и проведена их типизация с учетом психофизиологических параметров.

Определено, что особого внимания требуют судовые специалисты с высокими показателями нейротизма, психотизма и личностной тревожности, попавшие в группу «риска» и требующие психологического сопровождения, с целью фрормирования у них повышенных адаптационных возможностей организма к условиям стресса, связанного с профессией моряка.

Ключевые слова: индивидуально-типологические особенности, нейротизм, психотизм.

Постановка проблемы. По данным [1, с. 49-56; 2; 3, с. 103-105], одним из актуальных вопросов современных психолого-социальных исследований безопасности судовождения и работы в море является изучение механизмов реагирования членов плавсостава к экстремальным условиям труда.

Как считают авторы [4; 5], трудовая деятельность плавсостава является специфической и комплексной формой активного приспособления к окружающей и техногенной среде.

В последнее десятилетие изменилось понимание роли человеческого фактора в профеессиональной деятельности моряков: резко усилился интерес к изучению потребностей современного судового специалиста как профессионала, его ценностных представлений, социально-нормативных установок.

Так, по данным [3; 4; 6, с. 66-73; 7, с. 47-56; 8, с. 31-36], все факторы, объединенные в общее понятие «судовая среда», в течение длительного времени оказывают неблагоприятное воздействие на организм человека.

Факторы стресса $[1 ; 3 ; 9 ; 10]$, обусловливающие понятие «судовая среда», которые вызывают ряд психофизиологических нарушений у моряков, можно объединить следующим образом: относительная социальная изоляция, отсутствие важных отношений; информационный голод, недозагрузки 
анализаторов в условиях судовой изоляции (сенсорная депривация), невозможность удовлетворения ряда психофизиологических потребностей; стрессоры при взаимодействии непосредственно с рабочей средой судна (вибрации, излучения, загазованность, искусственное освещение, шум и т.д.); стрессоры от взаимодействия с замкнутой социально-психологической среде экипажа; семейно-бытовые фракторы стресса; постоянное напряжение от повышенной ответственности (угроза травм, аварий, пиратских захватов); различные непреодолимые стресс-фракторы - смена часовых поясов, угроза штормов и тайфунов; недостаточность двигательной активности (гипокинезия и гиподинамия).

Наиболее важной также является проблема проведения моряками свободного времени как в условиях рейса, так и, в межрейсовый период. По данным [1, с. 49-56; 4; 5; 9], ряд серьезных морских инцидентов напрямую связаны с употреблением алкоголя и психотропных веществ.

По данным [6, с. 66-73; 7, с. 47-56; 8, с. 31-36; 9; 10], на распространенность психосоматических нарушений среди членов судовой команды оказывает неблагоприятное влияние длительное нервно-психическое напряжение.

Выделяют следующие виды профессиональной напряженности в соответствии с теми психическими функциями, которые преимущественно вовлечены в профессиональную деятельность моряков и изменения которых наиболее выражены в неблагоприятных условиях профессиональной деятельности: интеллектуальное напряжение, вызванное частым обращением к интеллектуальным процессам при формировании плана обслуживания, что обусловлено высокой плотностью потока проблемных ситуаций обслуживания; сенсорное напряжение, вызванное неоптимальными условиями деятельности сенсорных и перцептивных систем и возникающее в случае больших затруднений в восприятии необходимой информации; монотония как напряжение, вызванное однообразием выполняемых действий, невозможностью переключения внимания, повышенными требованиями к концентрации и устойчивости внимания; политония как напряжение, вызванное необходимостью переключения внимания, часто в неожиданных направлениях; фризическое напряжение организма, вызванное повышенной нагрузкой на двигательный аппарат человека; эмоциональное напряжение, вызванное конфликтными условиями, повышенной вероятностью возникновения аварийной ситуации, неожиданностью или длительным напряжением других видов; напряжение ожидания вызвано необходимостью поддержания готовности рабочих функций в условиях отсутствия деятельности; мотивационное напряжение, связанное с борь- бой мотивов, с выбором критериев для принятия решения; утомление как напряжение, связанное с временным снижением работоспособности, вызванным длительной работой и др.

Однако проблема факторов, обусловливающих надежность профессиональной деятельности среди плавсостава, обеспечивающих его социально-психологическое благополучие, а следовательно, и безопасность судовождения, недостаточно изучена.

Поэтому вопросы сохранения как психического, так и физического здоровья моряка, его профилактики в межрейсовый период, улучшения условий профессиональной деятельности, режима труда и отдыха являются наиболее актуальной психолого-социальной проблемой и требуют своего изучения.

Целью исследования является изучение индивидуально-типологических особенностей у плавсостава, формирующихся под влиянием экстремальных факторов работы в море, проведение их типизации.

Методы исследования: субъективные и объективные методы исследования психофизиологических параметров: функциональные исследования, осмотр, опрос, беседа, интервью; методика определения свойств темперамента (тест Айзенка Г.), определение уровня тревожности (методика Спилбергера-Ханина).

Результаты исследования. Исследуемая группа представлена таким образом: 365 судовых специалистов (180 судоводителей и 185 судомехаников), мужчины в возрасте от 22 до 63 лет (данные профосмотров).

С целью выявления психологических факторов, оказывающих влияние на эмоциональное благополучие моряков, использовалась методика определения свойств темперамента (тест Айзенка Г.), позволяющая диагностировать такие личностные особенности судовых специалистов, как экстраверсия, интроверсия, эмоциональная стабильность-нестабильность (нейротизм).

В результате исследования выявлено, что среди капитанов старше 56 лет с опытом работы более 17 лет 84\% имеют низкий уровень нейротизма, психотизма и умеренной личностной тревожности, что говорит о высокой психической устойчивости, эмоциональной лабильности и наименьшей подверженности нервным срывам.

Однако $16 \%$ капитанов имеют высокий уровень нейротизма, психотизма и личностной тревожности, что нередко сопровождается склонностью к асоциальному поведению, употреблением алкоголя, наркотиков, повышенной конфликтностью и раздражимостью.

Данная категория морских специалистов составляет группу «риска» в управленческой деятельности, которой необходимо рекомендо- 
вать регулярное психологическое сопровождение (индивидуальные консультации психолога, психологические тренинги, саморегуляция поведения и т.д.) после окончания каждого рейса, так как свойства темперамента и личностная тревожность являются одними из факторов трудовой деятельности.

Профессиональная деятельность капитанов в возрасте от 36 до 55 лет является наиболее продуктивной, а среди лиц старше 56 лет часто встречаются судовые специалисты с превосходным психологическим статусом. Это сочетается с ответственным отношением к делу.

У старших помощников капитана группу «риска» составили 20\% специалистов. Высокие показатели нейротизма, психотизма и ситуативной тревожности (высокой и низкой) наблюдались у лиц в возрасте 46-55 лет, они были обусловлены ситуациями профессиональной деятельности.

Анализ показателей ситуативного реагирования показал, что высокая тревожность может стать причиной неправильного реагирования на сложившуюся ситуацию на судне. Низкая тревожность свидетельствует о безразличии, равнодушии и неготовности к решению профессиональных задач. Так, анализ данных показал, что у вахтенных помощников капитана наибольший процент нейротизма, психотизма и личностной тревожности (9\%) также приходится на возраст от 46 до 55 лет. Следовательно, уровень тревожности обусловлен ситуацией профессиональной деятельности.

Наиболее часто аварийные ситуации происходят в механико-котельном отделении, и на данных специалистах (старший и вахтенный механики) лежит круглосуточная ответственность за обеспечение безотказной работы судовых механизмов, основной возраст которых составляет 46-55 лет.

Так, анализ данных показал, что до 20\% судомехаников имеют высокий уровень нейротизма, психотизма и личностной тревожности. Это обусловлено тем, что профессиональная деятельность вахтенных механиков требует ответственного поведения в экстремальной ситуации и умения принимать самостоятельные решения.

Однако осознание того, что окончательное решение и ответственность за его принятие лежит на старшем механике, приводит к более низким психическим нагрузкам на нервную систему его подчиненных. Данная профессиональная категория составила 11\%, основной возраст - 46-55 лет, по-прежнему отмечается высокий уровень нейротизма, психотизма и личностной тревожности.

Тенденция к сокращению численности членов судового экипажа привела к невостребованности на судне ряда специалистов морских профессий со стажем работы в море по своей специальности более 15 лет, вынужденных проходить перепод- готовку по другой специальности (чаще всего на судового механика), что дает возможность продолжать работу в море. Высокий уровень тревожности среди этих членов экипажа обусловлен ситуацией профессиональной деятельности.

Поэтому данная категория судовых специалистов также попадает в группу «риска» и нуждается в особом внимании психологической службы для организации их психологического сопровождения после окончания рейса.

Основу диффреренциации в ходе проведения исследования составило состояние нейродинамических процессов обследуемых, отражающее проявление основных свойств силы нервной системы, подвижности и уравновешенности нервных процессов.

Так, признаками психического напряжения является: мобилизация психической деятельности, повышение активности соматического функционирования, чувство общего подъема физических и душевных сил. При этом психофизическая реакция моряков на стресс имеет биполярную выраженность и может быть представлена двумя основными типами - «лабильным» и «ригидным», определяемыми нейродинамическими особенностями моряков со своими специфическими адаптивно-компенсаторными реакциями.

Изучение влияния типологических особенностей нервной деятельности на адаптивные возможности к экстремальным условиям подтверждает значение силы возбудительного процесса как фрактора, обеспечивающего устойчивость к стрессовым воздействиям. В случаях несоответствия индивидуально-типологических особенностей человека профессиональным нагрузкам работы в море развивается комплекс негативных хронических эмоций, не только изменяющий психический статус моряка, но и нарушающий функциональное состояние центральной и вегетативной нервных систем организма.

Важно то, что психоэмоциональное реагирование на любую, даже незначительную стрессогенную ситуацию оказывает более выраженное влияние на состояние сердечнососудистой системы. Степень напряжения регуляторных систем при равных условиях трудовой деятельности на судне в силу конституционально-генетической детерминации психофизиологических показателей индивида проявляется по-разному, что обусловливает возможность типизации плавсостава по выраженности специфических адаптивных реакций.

На связь нейрофизиологических механизмов стресса с механизмами возникновения отрицательных эмоций указывают [8], функционально объединяя их с лимбической системой и гипоталамусом, которые, в свою очередь, функционально взаимосвязаны с корой и ретикулярной формацией, что затрудняет выявление структуры, ответственной за 
тот или иной вид поведения. Участие в формировании стрессовых реакций нервной регуляции делает актуальным вопрос о том, как реализуются при стрессе типологические особенности ЦНС.

Так, важное значение эти факторы приобретают для экстравертов, которые хуже переносят длительную психосенсорную изоляцию в силу своей склонности к эмоциональному контакту и необходимости в постоянном общении. Поэтому для интровертов и экстравертов длительные психотравмирующие ситуации, связанные с профессиональной деятельностью работы в море, могут приводить к значительным изменениям психоэмоционального и социального благополучия.

Высокие показатели по шкале психотизма свидетельствуют о склонности личности к асоциальному поведению, неадекватности эмоциональных реакций и выраженной конфликтности (определение уровня тревожности по методике Спилбергера-Ханина).

Судовые специалисты, отличающиеся повышенной тревожностью, стараются избегать ответственных заданий, а при необходимости решения сверхответственных задач могут впадать в состояние, близкое к панике. Личностная тревожность в этих случаях становится чрезвычайно высокой и провоцирует высокую ситуативную тревожность, которая может стать причиной неправильного реагирования на стрессовую ситуацию.

Таким образом, большинство судовых специалистов имеют необходимые базовые свойства, лежащие в основе профессионально важных качеств моряков, а учет индивидуально-психологических свойств личности применительно к экстремальным, аварийным ситуациям возрастает. Особого внимания требуют судовые специалисты с высокими показателями нейротизма, психотизма и личностной тревожности, попавшие в группу «риска» и требующие психологического сопровождения, т.е. специальной психологической подготовки, предполагающей не просто выполнение рекомендаций психолога, но и осознание необходимости их выполнять.

Однако на сегодня недостаточно разработана система психологического сопровождения членов плавсостава, которая должна охватывать все периоды жизнедеятельности моряка, включая дорейсовый, во время рейса и, особенно важный, - послерейсовый периоды.

Психологическое сопровождение моряка позволяет решить ряд важных задач по формированию психологической культуры, исключающей возможность сознательного нарушения правил безопасного мореплавания, повышающей психологическую устойчивость членов судового экипажа в экстремальной ситуации и способствующей повышению адаптации организма к условиям стресса.
Выводы. Проведено исследование индивидуально-типологических особенностей у плавсостава, формирующихся под влиянием экстремальных факторов работы в море, проведена их типизация с учетом психофизиологических параметров.

Подчеркнуто, что психофизическая реакция моряков на стресс имеет биполярную выраженность, которая представлена двумя типами: «лабильным» и «ригидным».

Выявлено, что среди капитанов старше 56 лет с опытом работы более 17 лет 84\% имеют низкий уровень нейротизма, психотизма и умеренной личностной тревожности, что указывает на высокую психическую устойчивость, эмоциональную лабильность и наименьшую подверженность нервным срывам.

Показано, что особого внимания требуют судовые специалисты с высокими показателями нейротизма, психотизма и личностной тревожности, попавшие в группу «риска» и требующие психологического сопровождения, с целью формирования у них повышения адаптационных возможностей организма к условиям стресса, связанного с профессией моряка.

\section{Литература:}

1. Кубасов Р.В. Условия жизнедеятельности экипажа на борту морского судна (обзор литературы). Вестник Государственного универcumema морского и речного фолота имени адмирала С.О. Макарова. 2016. № 2(36). C. 49-56.

2. Колегаєв М.А., Іванов Б.Н., Басанец Н.Г. Безопасность жизнедеятельности и выживание на море : учеб пособие. Одесса : ОНМА. 2007. 352 с.

3. Рымина Т.Н., Пятырова Е.В. Особенности воздействия стресса на работников плавсостава в условиях работыв море. Здоровье. Медицинская экология. Наука. 2014. № 4(58). С. 103-105.

4. НикитинаВ.Н. Особенностипрофессиональной деятельности моряков на автоматизированных судах и здоровье экипажа. Профилактическая медицина-2016: материалы Всероссийской научно-практической конфреренции с международным участием. 15-16 ноября 2016 года. Санкт-Петербург : Изд-во СЗГМУ им. И. И. Мечникова, 2016. С. 88-93.

5. Козлов В.В. Человеческий фрактор как современная методология обеспечения надежного функционирования эргатических систем. Безопасность жизнедеятельности. 2004. № 7.

6. Панов Б.В., Балабан С.В., Чебан С.Г., Самысько Д.Б., Лисобей В.А. Состояние здоровья моряков по результатам предварительных и периодических осмотров. Сообщение первое: медико-статистическая характеристика моряков. Актуальные проблемы транспортной медицины. 2013. № 3(33). С. 66-73. 
7. Панов Б.В., Балабан С.В., Чебан С.Г., Самысько Д.Б., Лисобей В.А. Состояние здоровья моряков по результатам предварительных и периодических осмотров. Сообщение второе: показатели заболеваемости моряков разных возрастных и стажевых групп. Актуальные проблемы транспортной медицины. 2013. № 3(34). С. 47-56.
8. Мамаенко Ю.В. Психофизиологические корреляты профессиональной адаптации моряков. Актуальные проблемы транспортной медицины. 2010. № 1(19). С. 31-36.

9. Даниленко А.А. Психологические основы управления судовым экипажем. Санкт-Петербург, 2007.

10.Стрелкова О.В. Психология профессиональной деятельности моряков. Калининград, 2005.

Voloshenko M. A., Azarkina A. V. Individual psychological characteristics of the crew in the stress factor of professional activity

The article analyzes the individual typological features of the crew members, formed under the influence of extreme factors of work at sea and their typification is carried out taking into account the psychophysiological parameters.

It was determined that the issues of preserving both the mental and physical health of the seaman, their prevention during the inter-cruise period, the improvement of the conditions of professional activity, the regime of work and rest, are the most relevant psychological and social problem and require their study.

In order to identify the psychological factors that affect the emotional well-being of sailors, a methodology was used to determine the properties of temperament, which allows diagnosing such personality traits of ship specialists as extraversion, introversion, emotional stability and instability.

It was shown that the psychophysical reaction of sailors to stress has a bipolar severity, which is represented by two types: "labile" and "rigid". The degree of tension of regulatory systems under equal conditions of work on a ship, due to the constitutional genetic determination of the psychophysiological parameters of an individual, manifests itself in different ways, which makes it possible to typify the crew according to the severity of specific adaptive reactions.

Analysis of the indicators of situational response showed that the level of anxiety is due to the situation of professional activity.

It is shown that most shipboard specialists have the necessary basic properties that underlie professionally important qualities associated with work at sea.

The basis of differentiation during the study was the state of the neurodynamic processes of the subjects, reflecting the manifestation of the basic properties of the strength of the nervous system, mobility and balance of the nervous processes.

The study of individual typological features in the crew, formed under the influence of extreme factors of work at sea, and their typification was carried out taking into account the psychophysiological parameters.

It has been determined that ship specialists with high rates of neurotism, psychotism and personal anxiety, who are in the risk group and require psychological support, require special attention to form their increased adaptive capabilities of the body to stress conditions associated with the profession of a sailor.

Key words: individual typological features, neuroticism, psychotic. 